\title{
Correspondence
}

\section{A reply to Professor Copeland}

Dear Sirs

We really cannot let the article by Professor Copeland (Psychiatric Bulletin, July 1992, 16, 391-395) pass without comment, especially because it carries the authority of the JCHPT.

First, and lest the reader should simply assume we are over-privileged Maudsley consultants, we wish to point out that the chill winds of NHS change have blown in our direction too, and that we also have to provide a good catchment service in one of the country's most deprived areas with dwindling resources. Furthermore, we regard it as one of our primary functions to offer to our junior staff the best training in service delivery, service innovation and research. It is not ourselves, we contend, who are overprivileged but rather that idealised senior registrar(SR) Professor Copeland and the JCHPT seek to create.

We are certainly able to agree with many of Copeland's 13 principles. It is the point he encapsulates in the phrase "trainees are supernumerary to the service" with which we take issue. A SR cannot be properly trained in a team where s/he is supernumerary to the service but only where $s /$ he is an integral part of that service. This means taking clinical responsibility, supervising other staff, and sometimes acting up for consultants when they are away. It certainly should not mean that the SR simply provides another ten fingers to put in the dyke against a flood of service work. Furthermore, we entirely agree that academic and research time should be protected where it is reasonable to do so. However, the JCHPT's charter for SRs implies that they are essentially higher students who should not carry responsibility for service delivery. This is surely most unrealistic. No one would like to be operated upon by a surgical SR who has to leave halfway through because his/her academic time is being eroded. Would the members of the JCHPT not agree that around $£ 24,500$ is rather high for a student grant? In the context of the NHS internal market it seems rather a lot to pay for a supernumerary.

The SR must not "act down", says Professor Copeland and, he adds, because consultants often act down that's no excuse because it is not adequate training. We could surely agree that acting down on a regular basis should not be built into a SR's job description, e.g. being required to perform the registrars' work when they go on annual leave, but this is really going too far. Every clinician frequently acts down because the irregular, unexpected and emergency nature of medicine demands it. Why should SRs be more protected than others from the real world? Surgical and internal medicine SRs are not, so what makes psychiatrists so special? The fact is that swallowing one's pride and acting down is excellent training for a consultant post.

Life in the NHS is not, of course, as Professor Copeland and the JCHPT wish to depict it. The great majority of our SRs, and the Joint Hospital has a good number, work hard in the service, put their patients first, and recognise that this is the way they are best trained. In return we offer them academic opportunities second to none and make every effort to ensure that academic, research and training times are properly protected. They understand that they are an integral part of the firms to which they are attached with defined and, we hope, reasonable service workloads. If at the end of their one-year attachment they are not replaced because it does not suit higher training needs, the work of that firm is seriously disrupted and patients suffer. Has the JCHPT ever considered this? Simply to pronounce that SRs must be supernumerary to service requirements is to bury one's head in the sand.

ROBIN JACOBY, GraHAM THORNICROFT Raymond LeVy, Parimala Moodley Klaus Bergmann, Gaius Davies Marisa Sil verman, Julian LefF Jeremy CHRISTIE BroWn, Brian TOONE Simon Wessely, ANThONY DAVID

The Maudsley Hospital

Denmark Hill

London SE5 $8 A Z$

\section{Reply}

DeAr Sirs

Thank you for asking me to reply to the Maudsley letter. First, it must be said that I cannot, of course, speak for the JCHPT of which I am no longer a member.

The Maudsley group disclaim privilege. Perhaps things have changed of recent years, but that is not the perception from the outside, particularly in terms of number of consultants and doctors in training. Put another way, consultants from most of the rest of the country still work in conditions that are very under-privileged and where the number of consultants per head of population still does not reach the College's old norms. Under these circumstances 
there is great pressure put on trainees to supplement the inadequate consultant numbers. This is understandable and acceptable to a point, but it has been the view that it is not acceptable when it impinges on academic activities. There is also pressure put on senior registrars in some places to substitute regularly for consultants acting on committees or when doing private practice, but I am sure these things never happen at the Joint Hospitals.

We would all join in the aspiration to provide the best training and service. I think that 'supernumerary' is not the ideal word for describing the way the Joint Committee views a senior registrar post. A better term might be sought. It is used to imply that the trainees are not permanent members of the team. While they must be integrally involved with the work of the service to which they are attached, they preserve the flexibility to move to other posts as their training needs require. Because the service is not dependent on them its quality is not impaired when they move. The Maudsley group ought perhaps to travel a little more outside London where most of the schemes in the country now accept and work well with the system of more training slots than salaries, enabling senior registrars to choose their posts. My own service will be without a senior registrar from October because none of our trainees needs to do liaison psychiatry at this time. The service I hope will not be impaired, although the consultants will have to take back some of the work load they shared with the senior registrar in exchange for his teaching time. A senior registrar must play as full a part in the service as is reasonably possible, substituting from time to time for the consultant and taking over from the consultant responsibility for a reasonable proportion of the work. The consultant gains time to teach the trainee. If senior registrars did not share in the full responsibility for the service, how else could they learn their job?

Regarding "acting down", it is regular and expected acting down which is objected to. It happened particularly in the old mental hospitals when difficult to fill registrar posts were converted to senior registrar posts to make them more attractive. In those days the job description did not change, only the money. Such traditions still linger in some places.

The JCHPT has set rules and guidelines but has rarely been rigid about their application when they judged that the spirit behind the training was right. I hope they have been determined when it was judged the spirit was not right.

The final paragraph of the letter seems more by way of an advertisement and I think I have dealt with the only point it makes

Royal Liverpool University Hospital

J.R.M. COPELAND

PO Box 147

Liverpool L69 3BX

\section{Clinical independence}

I submit that Dr T. D. Scannell's letter (Psychiatric Bulletin August 1992, 16, 509) merits placement under the vision of those holding power in the College. His final sentence "a doctor nowadays who questions, who tackles the system, who says "what of my patient though" is told he is shroud waving or that he is awkward, and he can now be threatened with dismissal" is as true as it is damning of the pass we are now in. This is a pass that is mortally threatening to proper standards for patients. It is a pass that those with power and preferment should be exploring for a juster future for those who dare speak unpopular thoughts, displeasing to the politics of mental health. If our leaders can honourably get the profession out of the morass, they will deserve recognition like those at Thermopylae!

The Coach House

HARRY JACOBS

Wormingford

Colchester, Essex

$\mathrm{CO6} 3 \mathrm{AH}$

\section{DeAr SirS}

Thank you for letting me see Dr Jacobs' letter. It is quite clear from the Supplemental Charter and Bye-Laws of the Royal College of Psychiatrists that Fellows and Members have a duty "the achievement and maintenance of the highest possible standards of professional competence and practice ... to give consideration to improve methods of hospital and other medical administration ... to consider, pronounce and make representations upon all questions affecting ... the promotion of improvements in the principles and administration of the law relating to mental disorder and to the treatment of persons suffering from mental and connected illnesses". Pointing out what is detrimental to the care of our patients is not only sanctioned, it is obligatory.

I know of no Fellow or Member of this College practising in the United Kingdom or Ireland who in carrying out this duty has been threatened with dismissal.

Professor A.C.P. Sims President

The Royal College of Psychiatrists

17 Belgrave Square

London SWIX 8 PG

\section{Psychotherapy in the reorganised NHS}

Dear Sirs

I practised as a psychotherapist in the NHS for nearly 25 years. My new patient waiting list was similar in length to those of my colleagues; medical students' attendance was good, and, so far as clinical 